\title{
Residual Stress Analysis of Mild Steel ASTM A36 in Milling \& Drilling
}

\author{
Abin Paul ${ }^{1}$, Akash Paul Savio ${ }^{2}$ \\ Viswajyothi College of Engineering and Technology, Muvattupuzha-686670, Kerala, India
}

\begin{abstract}
The significance of machining parameter optimization is increasing day by day in the current manufacturing scenario. Many large industries have attempted to introduce the highly automated and computer-controlled machines as their strategy to adapt to the ever-changing competitive market requirement. Due to high capital and machining costs, there is an economic need to operate these machines as efficiently as possible in order to obtain the required pay back. This research looks to fill gaps in current residual stress modeling techniques. In particular, the research will focus on predicting residual stresses in milling and drilling process. Mild steel ASTM A36 is the material used here. An investigation on influence of machining parameters such as number of teeth of the cutter (Zc) and depth of cut ( $t)$ for milling, feed $(S)$ and diameter of drill bit (d) for drilling. These parameters have large influence on the cutting force, and the response parameter is the residual stress. Experiments were conducted. Effects of input parameters on output responses were studied. The simulation is carried out with ANSYS workbench. And finally optimal parameter combination in milling and drilling is obtained.
\end{abstract}

Keywords: Drilling, Milling, Residual Stress Ansys Work Bench Stress Intesity

\section{Introduction}

Residual stresses play an important role in the performance of machined components. Component characteristics that are influenced by residual stress include fatigue life, corrosion resistance, and part distortion. The functional behavior of machined components can be enhanced or impaired by residual stresses. Because of this, understanding the residual stress imparted by machining is an important aspect of understanding machining and overall part quality.

The sources of residual stress are widely varied and include plastic deformation of a material or volume changes of a material due to thermal gradients. In the case of plastic deformation, the residual stress is due to the permanent displacement of the crystal structure. The residual stresses caused by thermal gradients are typically a result of a change in volume of the material.

In machining, all of the previously described sources of residual stress are present. Plastic deformation occurs during chip formation and contact between the tool and the machined part. Thermal gradients are produced by plastic deformation as well as frictional heating. If temperature and pressure are high enough, phase transformations on the newly generated surface may occur. Additionally, the effect of stress and temperature on the material behavior during loading may influence residual stresses. As a result, modeling the residual stress formation on a machined surface is a challenging task.

This research looks to fill gaps in current residual stress modeling techniques. In particular, the research will focus on predicting residual stresses in milling and drilling Mild steel ASTM A36 is the material used here. An investigation on influence of machining parameters such as number of teeth of the cutter $(Z c)$ and depth of cut $(t)$ for milling, feed $(S)$ and diameter of drill bit $(d)$ for drilling. These parameters have large influence on the cutting force, and the response parameter the residual stress. The modeling techniques can be applied to a range of machining operations including orthogonal cutting, broaching, drilling, milling, and turning.

Different approaches to the determination of residual stresses can be summarized as experimental measurements, finite element calculations and analytical models. Although it serves as the ultimate validation tool for numerical or analytical simulations, experimental approach is too costly to be utilized in every scenario. On the other hand, finite element modeling serves as a good simulation tool; however, it is too time-consuming even with state of the art computational resources. And finally, analytical modeling provides a fast alternative.

\section{Literature Review}

Most of the early efforts at determining the effect of machining on residual stress were experimental in nature. One of the pioneering efforts at assessing the residual stress due to machining was undertaken by Henriksen [2]. The publication presented fundamental experimentation and analysis that is still widely referenced today. Henriksen experimented on low-carbon steel orthogonally machined. The work concluded that mechanical and thermal effects played a role in the residual stress development, but mechanical influence dominated.

Liu and Barash tried to determine the effect of machining parameters on the residual stress in a machined surface [3]. They found that for orthogonal cutting, four variables uniquely determined the pattern of residual stress on a machined surface. The variables included the length of the shear plane, tool flank wear, shape of the cutting edge, and the depth of cut. The shape of the cutting edge determined the residual stress pattern near the machined surface. Additionally, the research found that tool flank wear increased cutting temperature. . Xie and Bayoumi [4] also investigated the effect of tool wear on residual stress in 


\section{International Journal of Science and Research (IJSR) \\ ISSN (Online): 2319-7064}

Index Copernicus Value (2015): 78.96 | Impact Factor (2015): 6.391

machining. They found similar results and concluded that tool wear impacted residual stress.

More recently, Jang used turning experiments on AISI 304 stainless steel to determine the effect of machining parameters [5]. Residual stresses were measured using X-ray diffraction. The work showed that the tool sharpness has a strong influence on the surface residual stress. Additionally, they showed that the principal stresses at the surface were close to the hoop and axial directions of the work piece.

Tsuchida et al [8] experimented on the effect of cutting conditions on the residual stress distribution. They performed tests in which speeds, feeds, and depths of cut were varied. They concluded that a decrease in the cutting speed decreases the tensile residual stress near the surface, and increases the depth of the residually stressed layer.

Mishra [17] developed an analytical model based on FEM to determine residual stresses due to a moving heat source. The model predicted the residual stresses of thermal and mechanical origin in a grinding process. The author discussed the effect of the magnitude of mechanical force, the rate of heat input, and the speed of movement of the work piece on the residual stresses.

Lin [18] used a finite element method to determine the strain field in the work piece. Using the strain field, the concept of particle flow was employed to determine the stress history of the strain history of the material. The modeling procedure introduced by Merwin and Johnson [12] was used to predict the residual stresses produced by machining. Lin incorporated both thermal and mechanical loads in the model. Trends from the model were compared with experimental data. Model boundary conditions such as shear angle were assumed to be known a priori. Another work by Lin and Lee [30] used the same modeling methodology but included the effect of flank wear.

\section{Experimental Procedure}

Experiment to find residual stress in both milling and drilling is done in order to validate the model. The residual stress is found out using crack compliance method.

General procedure to obtain residual stress by the $\mathrm{CC}$ method

- The machined work-piece is clamped on to the wire cut EDM machine.

- Cutting a slit at constant rate 'a' is done, at the same time strain is measured by a strain gauge which placed on the work-piece.

- Cutting length 'a' and the strain values are noted.

These values are substituted in the equations and residual stress is obtained [21]. And the equations are

$$
K_{I r S}(\mathrm{a})=\sigma \sqrt{\pi a} F_{t}
$$

Where

$\sigma$ is the stress acting on the work piece while slitting $K_{\text {Irs }}$ ( a) is the stress intensity factor due to residual stress, $a$ is the length of the cut, $F_{t}$ is the geometric function and is obtained from the chart.[]

$$
K_{I r S}(\mathrm{a})=\int_{0}^{a} h(x, a) \sigma_{r s} d x
$$

Where $h(x, a)$ denotes the so-called weight function, which is universal for a given crack geometry and available for many systems, Kirs $(a)$ is the stress intensity factor, $\sigma r s$ is the residual stress and by substituting all these in these equations, we can calculate the residual stress.

\section{A. Milling}

The work piece of size $10 \mathrm{~cm} \times 5 \mathrm{~cm} \times 3 \mathrm{~cm}$ is clamped in to the machine and a cut of depth $1 \mathrm{~mm}$ at $100 \mathrm{rpm}$ with cutter having 10 teeth is done. The cutter is of $144 \mathrm{~mm}$ diameter, the cutter material is HSS and cutter width is $5 \mathrm{~mm}$. During machining the work-piece undergoes plastic deformation and the stress induced in it after removing the load is the residual stress.

After machining, the work piece is placed into a wire cut EDM machine. Cutting a slit at constant rate is done, at the same time strain is measured by a strain gauge which placed on the work-piece. Cutting length ' $a$ ' and the strain values are noted. After that the values are substituted in the equations and residual stress is obtained. The work piece is cut up to $4.9 \mathrm{~cm}$ and the resultant strain values are measured. Now these values are substituted into the equations of crack compliance method. And finally residual stress is obtained. A graph is plot between residual stress and cut length which depends on the width of the work piece. The highest value from the graph is taken.

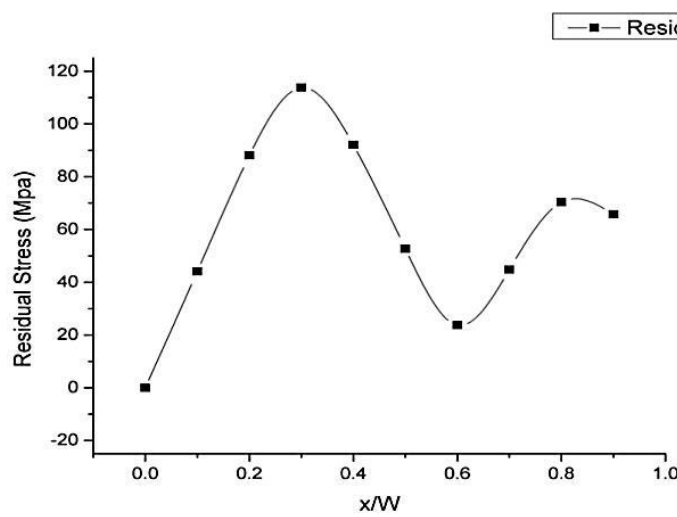

Figure 1: Graph between residual stress and cutting length.

We select the maximum value of residual stress from graph, and the residual stress obtained is $113.77 \mathrm{Mpa}$.

From the analysis it is found that, for the cutter having 10 teeth and cutting depth of $1 \mathrm{~mm}$, the residual stress obtained is $116.8 \mathrm{MPa}$. The experimental result is approximately equal to the analytical result. So our model is validated.

\section{B. Drilling}

For drilling we use drill bit of $8 \mathrm{~mm}$ diameter. The work piece of size $10 \mathrm{~cm} \times 5 \mathrm{~cm} \times 3 \mathrm{~cm}$ is through holed at a speed of $500 \mathrm{rpm}$ with a feed of $0.2 \mathrm{~mm} / \mathrm{rev}$. During the drilling operation work-piece undergoes plastic deformation and the stress induced in it after removing the load is the residual stress. 


\section{International Journal of Science and Research (IJSR) \\ ISSN (Online): 2319-7064 \\ Index Copernicus Value (2015): 78.96 | Impact Factor (2015): 6.391}

After drilling, the work piece is placed into a wire cut EDM machine. Cutting a slit at constant rate is done, at the same time strain is measured by a strain gauge which placed on the work-piece. Cutting length ' $a$ ' and the strain values are noted. After that the values are substituted in the equations and residual stress is obtained. The work piece is cut up to $4.9 \mathrm{~cm}$ and the resultant strain values are measured.. Now these values are substituted into the equations of crack compliance method. And finally residual stress is obtained. A graph is plot between residual stress and cut length which depends on the width of the work piece. The highest value from the graph is taken.

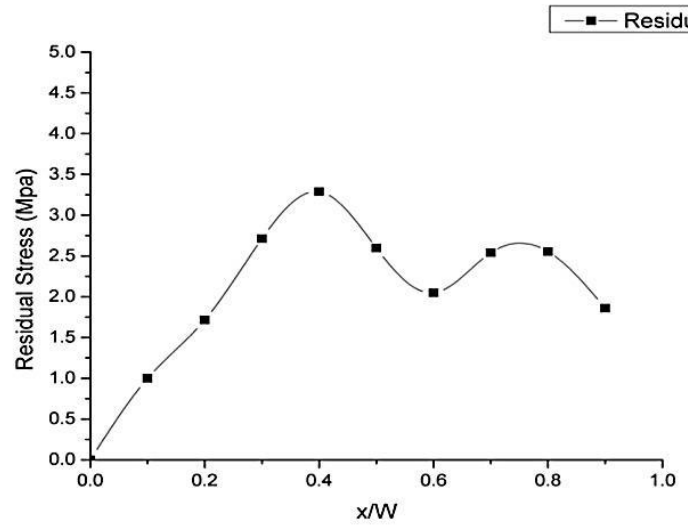

Figure 2: Graph between residual stress and cutting length

We select the maximum value of residual stress from graph

And the residual stress obtained is $3.31 \mathrm{Mpa}$.

From the analysis it is found that, for the feed of $0.2 \mathrm{~mm} / \mathrm{rev}$ and tool diameter of $8 \mathrm{~mm}$, the residual stress obtained is $3.8716 \mathrm{MPa}$. The experimental result is approximately equal to the analytical result. So our model is validated.

\section{Analysis and Optimization}

For the analysis in milling and drilling, cutting force is taken as the input. For that, there are some equations to find the cutting forces [20].

\section{A. Cutting forces in milling}

The resultant force acting on the work piece is

$$
R=\sqrt{F_{m t}^{2}+F_{r}^{2}}(3)
$$

Where $F \mathrm{mt}$ is the mean tangential cutting force in $\mathrm{N}, F \mathrm{r}$ is the radial component of force in $\mathrm{N}$.

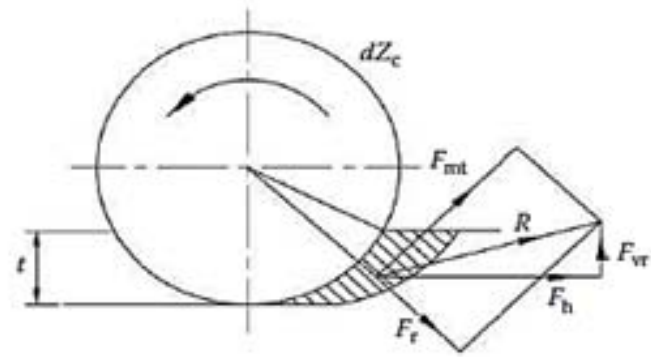

The totas mean tangential cutting force, $F \mathrm{mt}$

$$
F m t=\left(K_{s} t f b_{w}\right) / \pi d N
$$

Where $k_{s}$ is the specific cutting energy $\left(\mathrm{N} / \mathrm{mm}^{2}\right)$, $\mathrm{t}$ is the depth of cut $(\mathrm{mm}), \mathrm{f}$ is the feed rate $(\mathrm{mm} / \mathrm{min}), b_{w}$ is the milling cutter width $(\mathrm{mm}), \mathrm{d}$ is the diameter of the cutter $(\mathrm{mm}), \mathrm{N}$ is the rotational speed (rev/min).

The radial component of force, $F r$

$$
F r=\text { yield strength } t \quad b_{w}
$$

Where $t$ is the depth of cut (mm), $b_{w}$ is the milling cutter width (mm).

We know the angle of cut, $\Theta$

$$
\Theta=\tan ^{-1}\left(\frac{F m t}{F r}\right)
$$

So by finding the cutting angle, we can find the cutting force on horizontal and vertical direction.

The cutting force acting on horizontal direction, $F h$

$$
F h=R \cos \theta
$$

Where $\mathrm{R}$ is the resultant force $(\mathrm{N}), \Theta$ is the cutting angle

The cutting force acting on the vertical direction, $\mathrm{Fr}$

$$
F r=R \sin \theta
$$

Where $\mathrm{R}$ is the resultant force $(\mathrm{N}), \Theta$ is the cutting angle

For each combination of parameter, we have to find the cutting forces.

\section{B. Cutting forces in drilling}

The main cutting force $F_{\mathrm{V}}$ acting on each lip can be calculated from

$$
F \mathrm{v}=k \mathrm{~s} A \mathrm{c}
$$

Where $k \mathrm{~s}$ is the specific cutting energy $\left(\mathrm{N} / \mathrm{mm}^{2}\right), A \mathrm{c}$ is the chip cross-sectional area $\left(\mathrm{mm}^{2}\right)$

And the moment or torque M,

$$
M=M V=F V \frac{d}{2}
$$

Where $F v$ is the cutting force $(\mathrm{N}), \mathrm{d}$ is the diameter of the drill bit (mm).

For each combination of parameter, we have to find the cutting force and moment.

The models predictions will then be validated with experimental data do determine the effectiveness of the modelling technique. For this we use software called ANSYS.

Figure 3: Resolution of cutting forces in up milling 


\section{International Journal of Science and Research (IJSR) \\ ISSN (Online): 2319-7064 \\ Index Copernicus Value (2015): 78.96 | Impact Factor (2015): 6.391}

\section{Results \& Discussions}

Here the effect of input parameters on the output response, and optimal parameter combination based on analysis using ANSYS in milling and drilling is obtained.

\section{A. Milling}

The main result obtained from the ANSYS analysis for different parameters such as number of teeth and depth of cut is given in the table below and the optimum combination is the combination which having the minimum residual stress.

Table 1: Analysis result of milling.

\begin{tabular}{|c|c|c|c|}
\hline Sl no & $\begin{array}{c}\text { Depth Of } \\
\text { Cut, t (mm) }\end{array}$ & $\begin{array}{c}\text { No Of Teeth } \\
, Z c\end{array}$ & $\begin{array}{c}\text { Residual Stress } \\
(\mathrm{MPa})\end{array}$ \\
\hline 1 & \multirow{3}{*}{1} & 10 & 116.8 \\
\hline 2 & & 12 & 119.28 \\
\hline 3 & & 14 & 239.75 \\
\hline 4 & \multirow{3}{*}{2} & 10 & 120.96 \\
\hline 5 & & 12 & 158.9 \\
\hline 6 & & 14 & 243.08 \\
\hline 7 & & 10 & 108.56 \\
\hline 8 & & 12 & 160.61 \\
\hline 9 & & 14 & 246.43 \\
\hline
\end{tabular}

The optimum parameter combination obtained from the analysis is for the cutter having 10 teeth and cutting depth of $3 \mathrm{~mm}$.

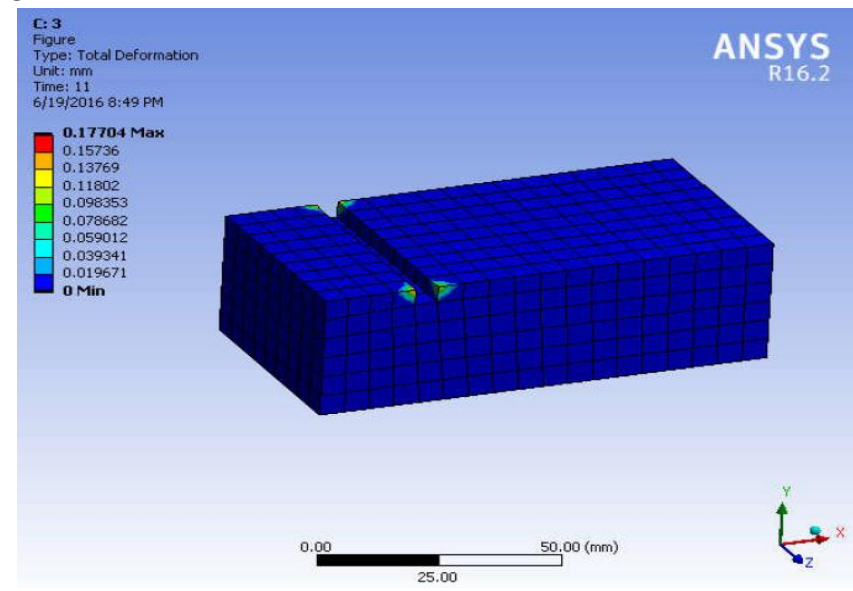

Figure 4: Total deformation of the workpiece.

The residual stress is the stress acting on the work piece after the load is removed.

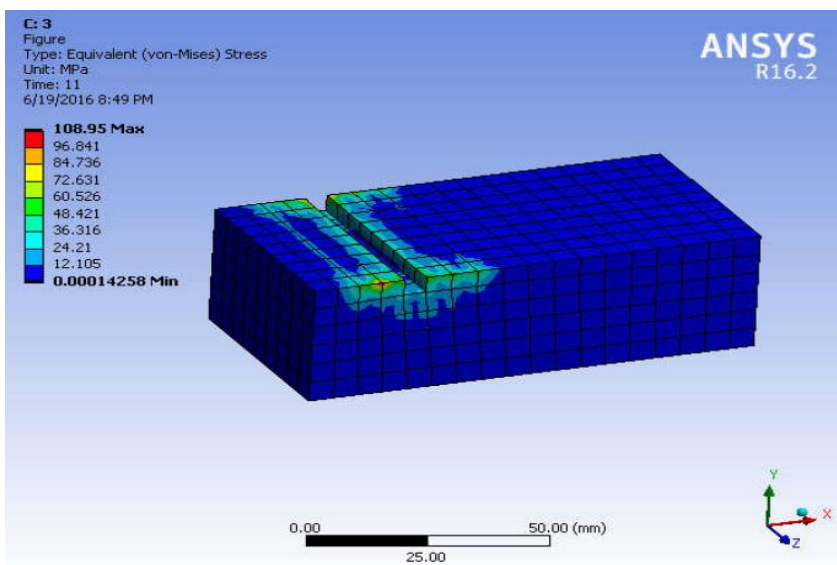

The residual stress obtained for the optimum parameter combination of the cutter having 10 teeth and cutting depth of $3 \mathrm{~mm}$ is $108.56 \mathrm{MPa}$.

\section{B. Drilling}

The main result obtained from the ANSYS analysis for different parameters such as feed and diameter of the drill bit is given in the table below and the optimum combination is the combination which having the minimum residual stress Here the feed of $0.2 \mathrm{~mm} / \mathrm{rev}, 0.4 \mathrm{~mm} / \mathrm{rev}, 0.6 \mathrm{~mm} / \mathrm{rev}$ are taken and tool diameter of size $8 \mathrm{~mm}, 10 \mathrm{~mm}, 12 \mathrm{~mm}$ is taken.

Table 2: Analysis of result of drilling

\begin{tabular}{|c|c|c|c|}
\hline$S N o$ & Tool diameter $(\mathrm{mm})$ & Feed $(\mathrm{mm} / \mathrm{rev})$ & $\begin{array}{c}\text { Residual Stress } \\
\text { (Mpa) }\end{array}$ \\
\hline 1 & \multirow{3}{*}{8} & 0.2 & 3.8716 \\
\hline 2 & & 0.4 & 7.7432 \\
\hline 3 & & 0.6 & 11.615 \\
\hline 4 & \multirow{3}{*}{10} & 0.2 & 4.8667 \\
\hline 5 & & 0.4 & 6.3567 \\
\hline 6 & & 0.6 & 14.2667 \\
\hline 7 & \multirow{3}{*}{12} & 0.2 & 7.1067 \\
\hline 8 & & 0.4 & 16.9667 \\
\hline 9 & & 0.6 & 12.8467 \\
\hline
\end{tabular}

The optimum parameter combination obtained from the analysis is for feed of $0.2 \mathrm{~mm} / \mathrm{rev}$ and tool diameter of $8 \mathrm{~mm}$.

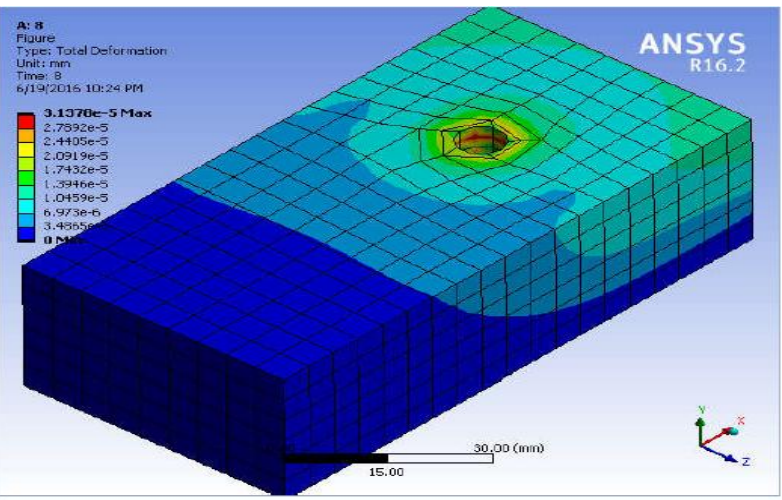

Figure 6: Total deformation of the workpiece

The residual stress is the stress acting on the work piece after the load is removed.

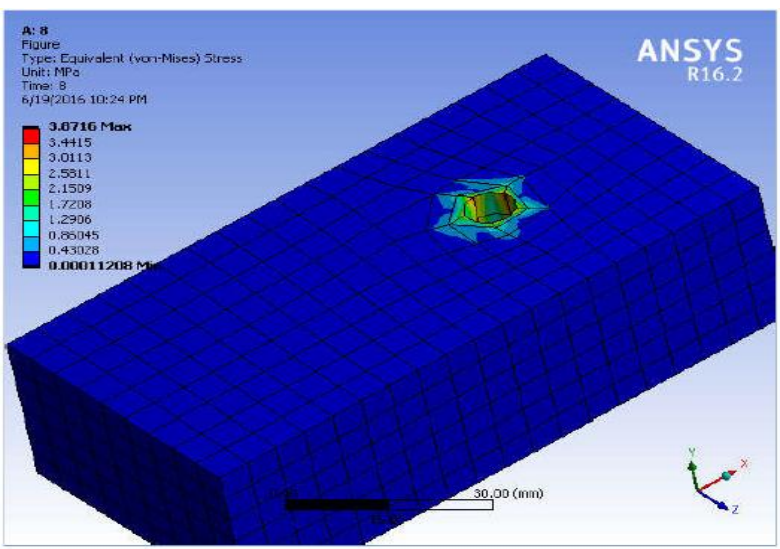

Figure 7: Residual stress acting on the work piece

Figure 5: Residual stress acting on the work piece

Volume 6 Issue 1, January 2017 


\section{International Journal of Science and Research (IJSR) \\ ISSN (Online): 2319-7064 \\ Index Copernicus Value (2015): 78.96 | Impact Factor (2015): 6.391}

The residual stress obtained for the optimum parameter combination of the feed of $0.2 \mathrm{~mm} / \mathrm{rev}$ and tool diameter of $8 \mathrm{~mm}$ is $3.8716 \mathrm{MPa}$.

\section{Conclusion}

The significance of machining parameter optimization is increasing day by day in the current manufacturing scenario. Many large industries have attempted to introduce the highly automated and computer-controlled machines as their strategy to adapt to the ever-changing competitive market requirement. Due to high capital and machining costs, there is an economic need to operate these machines as efficiently as possible in order to obtain the required pay back.

In this present work, residual stresses occurring due to thermo-mechanical effect of machining processes are investigated. The parameter for milling and drilling operation is optimized. Literature reviews on optimization were done. The machining parameters selected were number of teeth of the cutter $(\mathrm{Zc})$ and depth of cut $(\mathrm{t})$ for milling, feed (S) and diameter of drill bit (d) for drilling. These parameters have large influence on the cutting force. These are the input parameters and the response parameter is the residual stress. Experiments were conducted to find the residual stress for milling and drilling. ANSYS software was used for analysis the result and these responses were validated experimentally. From the analysis result we have found the optimal combination of parameters for milling and drilling, which generates lowest residual stress. For milling, the residual stress obtained for the optimum parameter combination of the cutter having 10 teeth and cutting depth of $3 \mathrm{~mm}$ is $108.56 \mathrm{MPa}$. For drilling, the residual stress obtained for the optimum parameter combination of the feed of $0.2 \mathrm{~mm} / \mathrm{rev}$ and tool diameter of $8 \mathrm{~mm}$ is $3.8716 \mathrm{MPa}$.

As for future works, we can change the specimen material, can consider the temperature during the machining process, can change the parameters, and can change the machining operation.

\section{References}

[1] Noyan, I.C. and J.B. Cohen, Residual Stress : Measurement by Diffraction and Interpretation. 1987, New York: Springer-Verlag. x, p. 276

[2] Henriksen, E.K., Residual Stresses in Machined Surfaces. American Society of Mechanical Engineers Transactions, 1951. 73(1): p. 69-76.

[3] Liu, C.R. and M.M. Barash, Variables Governing Patterns of Mechanical Residual Stress in a Machined Surface. Journal of Engineering for Industry, Transactions ASME, 1982. 104(3): p. 257-264.

[4] Xie, Q., et al. A Study on Residual Stresses and Tool Wear Induced by the Machining Process. in NAMRC XVII. 1989: SME.

[5] Jang, D.Y., et al., Surface Residual Stresses in Machined Austenitic Stainless Steel. Wear, 1996. 194(1-2): p. 168-173.

[6] Matsumoto, Y., F. Hashimoto, and G. Lahoti, Surface Integrity Generated by Precision Hard Turning. CIRP Annals - Manufacturing Technology, 1999. 48(1): p. 59-62.
[7] Mamalis, A.G., J. Kundrak, and K. Gyani, On the Dry Machining of Steel Surfaces Using Superhard Tools. International Journal of Advanced Manufacturing Technology, 2002. 19(3): p. 157-162.

[8] Tsuchida, K., Y. Kawada, and S. Kodama, Study on the Residual Stress Distributions by Turning. 1975. 18(116): p. 123-130.

[9] Matsumoto, Y., M.M. Barash, and C.R. Liu, Effect of Hardness on the Surface Integrity of AISI 4340 Steel. Journal of Engineering for Industry, Transactions ASME, 1986. 108(3): p. 169-175.

[10]Fuh, K.-H. and C.-F. Wu, Residual-Stress Model for the Milling of Aluminum Alloy (2014-T6). Journal of Materials Processing Technology, 1995. 51(1-4): p. 87105.

[11] Jacobus, J.K., R.E. DeVor, and S.G. Kapoor, Machining-Induced Residual Stress: Experimentation and Modeling. Journal of Manufacturing Science and Engineering, 2000. 122: p. 20-31.

[12] Merwin, J.E., Johnson, K.L., An Analysis of Plastic Deformation in Rolling Contact. Proeedings, Institution of Mechanical Engineers, London, 1963. 177(25): p. 676-685

[13] Mittal, S. and C.R. Liu, Method of Modeling Residual Stresses in Superfinish Hard Turning. Wear, 1998. 218(1): p. 21-33.

[14]El-Axir, M.H., A Method of Modeling Residual Stress Distribution in Turning for Different Materials. International Journal of Machine Tools \& Manufacture, 2002. 42(9): p. 1055-63.

[15] Sridhar, B.R., et al., Effect of Machining Parameters and Heat Treatment on the Residual Stress Distribution in Titanium Alloy Imi-834. Journal of Materials Processing Technology, 2003. 139(1-3 SPEC): p. 628634.

[16] Okushima, K. and Y. Kakino, Residual Stress Produced by Metal Cutting. CIRP Annals, 1971. 20(1): p. 13-14.

[17] Mishra, A. and T. Prasad, Residual Stresses Due to a Moving Heat Source. International Journal of Mechanical Sciences, 1985. 27(9): p. 571-581.

[18]Lin, Z.-C., Y.-Y. Lin, and C.R. Liu, Effect of Thermal Load and Mechanical Load on the Residual Stress of a Machined Workpiece. International Journal of Mechanical Sciences, 1991. 33(4) p. 263-278.

[19]D. Ulutan, B. ErdemAlaca, I. Lazoglu, Analytical modelling of residual stresses in machining. Journal of Materials Processing Technology 183 (2007): p. 77-87.

[20] Fundamentals of machining processes conventional and nonconventional processes. A text book by ElHofy, Hassan, Taylor \& Francis (2014).

[21] Tada, H., Paris, P.C., Irwin, G.R., The stress analysis of cracks handbook, Del Research Corporation, 1986. 